\title{
Peito escavado (Pectus excavatum)
}

\section{Funnel chest (Pectus excavatum)}

\author{
Rosana Pinheiro Botelho', Fernanda Rabello de Castro , Ricardo Siqueira da Silva', Ana Cristina \\ Cattete Quevedo²
}

\section{Resumo}

O caso de um canino com Pectus excavatum, no qual utilizamos uma técnica não invasiva para a correção anatômica do tórax, com resultado satisfatório, é apresentado.

\section{Palavras chave: Pectus excavatum; tórax; cão}

Pectus excavatum é uma enfermidade congênita, caracterizada por compressão dorso-ventral e aumento da largura torácica, com maior incidência em cães de raças braquicefálicas, não apresentando predisposição sexual nesta espécie.

A literatura cita a ocorrência de apenas um caso na raça Cocker Spaniel (Fossum et al., 1989a), dos 14 relatados (Fossum et al., 1989b).

No presente trabalho um canino da raça Cocker Spaniel, macho, com 15 dias de idade, pesando $160 \mathrm{~g}$, oriundo do cruzamento entre irmãos, atendido no setor de Cirurgia do Hospital Veterinário da Universidade Federal Rural do Rio de Janeiro, apresentava um quadro de impossibilidade de se manter em estação devido à lateralização dos membros torácicos, alteração morfológica do tórax com achatamento dorso-ventral, desenvolvimento corporal retardado, dispnéia, respiração abdominal, cianose, apatia, dificuldade de sugar o leite materno e aerofagia com conseqüente flatulência (Fig. 1).

O diagnóstico baseou-se na anamnese e no exame clínico, sendo confirmado através do exame radiográfico.

O tratamento objetivou a elaboração e execução de uma técnica não invasiva, baseada nas técnicas invasivas relatadas por Fossum et al. (1989a, b), Boudrieau et al. $(1989,1990)$ e Sweet e Waters (1991) possibilitando a compressão latero-lateral do tórax e o reposicionamento fisiológico do esterno.

Diante do laudo radiográfico, que evidenciou a presença de extremidades ventrais das costelas voltadas medialmente para unirem-se às esternebras e deslocadas dorsalmente, confeccionou-se um aparelho para permitir a correção anatômica das paredes torácicas, através de compressão latero-lateral, utilizando uma viga de alumí-

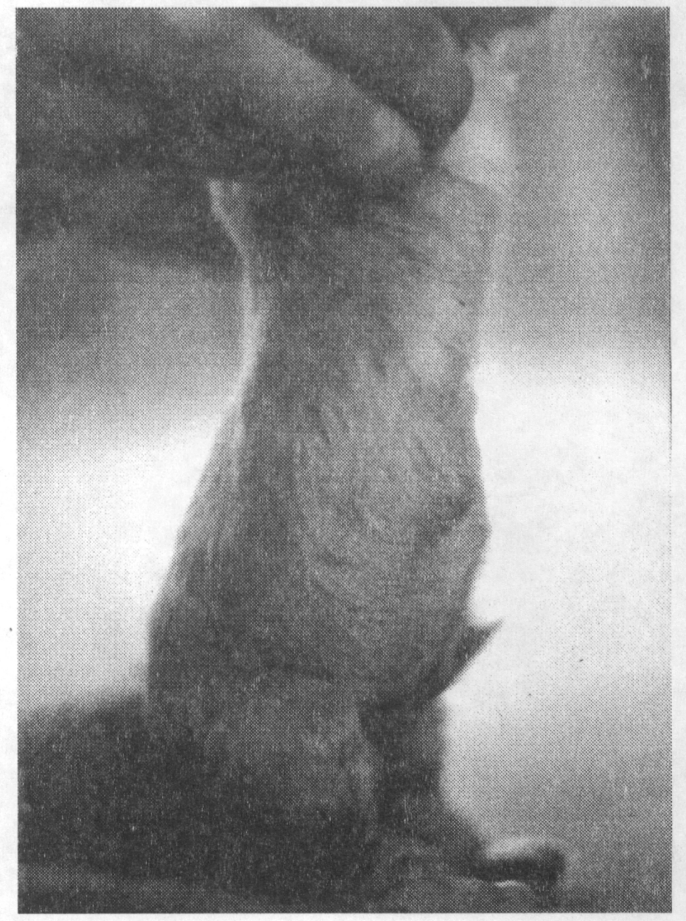

Figura 1 - Canino com peito escavado atendido no setor de Cirurgia do Hospital Veterinário da Universidada Federal Rural do Rio de Janeiro.

nio de $4 \mathrm{~mm}$ de diâmetro. Este material, de fácil manejo, foi moldado ao redor do tórax, em foma de "cela", acolchoado com algodão ortopédico, envolto em atadura de crepom e fixado ventralmente ao tórax com duas tiras de esparadrapo e cranialmente com uma tira (Fig. 2).

Revisões clínicas e radiográficas foram realizadas semanalmente permitindo as readaptações do aparelho ao corpo do animal. Após 30 dias o aparelho foi removido e aos 14 meses de idade o cão apresentava vida normal (Fig. 3).

O animal iniciou a deambulação em 10 dias, obtendo um bom desenvolvimento corporal, pela facilidade de alimentar-se e pelo conforto respiratório estabelecido. A conformação anatômica fisiológica do tórax foi obtida.

\footnotetext{
1 Universidade Federal Rural do Rio de Janeiro (UFRRJ), Km 47 da Antiga Rodavia Rio-São Paulo, 23851-970 Seropédica, RJ, Brasil

${ }^{2}$ Médica Veterinária Autônoma
} 


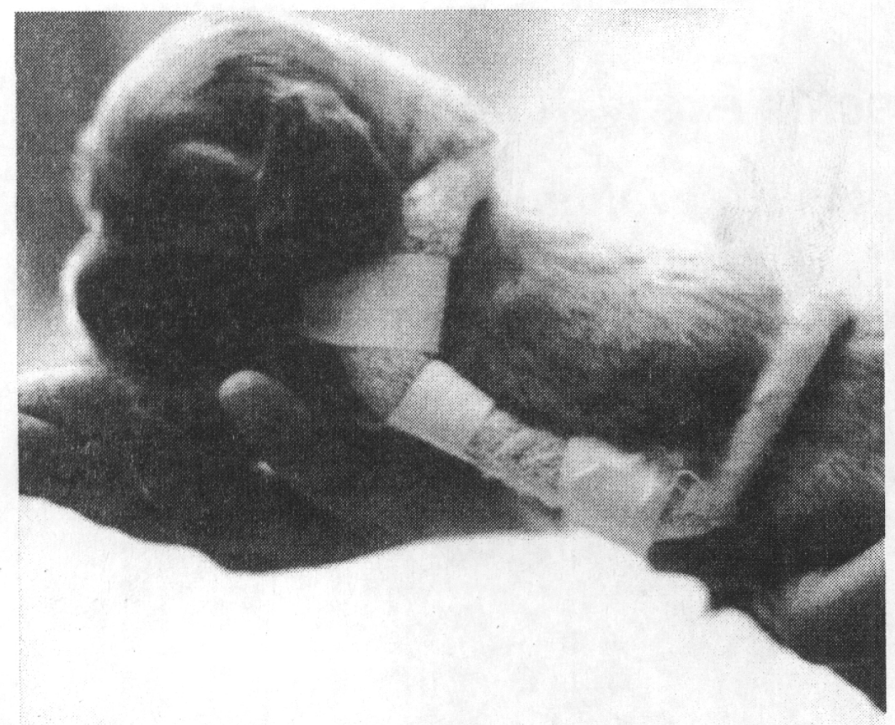

Figura 2 - Aparelho para permitir a correção anatômica das paredes torácicas.

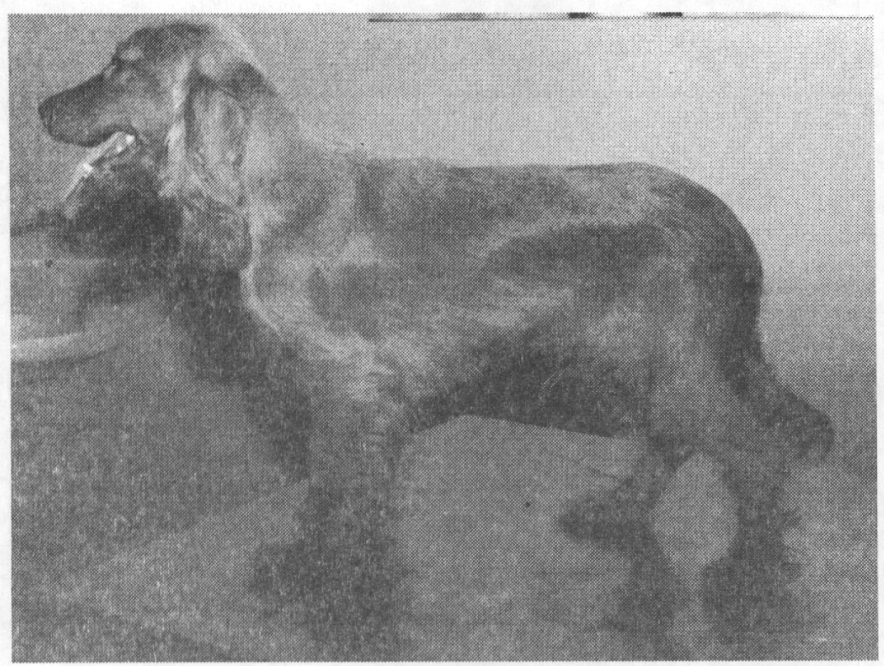

Figura 3 - Canino após retirada do aparelho, apresentando vida normal.

As técnicas invasivas consistem na fixação de armações externas (splintage) ao redor do esterno, utilizando suturas sob tensão. Podem causar perfuração da agulha no coração, pulmões e grandes vasos, além de necessitarem de um cirurgião experiente.
Os animais, extremamente jovens, apresentam alterações cardio-respiratórias, e ao serem submetidos à anestesia, apresentam-se como pacientes de alto risco anestésico (Boudrieau et al., 1989; Fossum et al., 1989b; Sweet e Waters, 1991).

A técnica não invasiva desenvolvida no presente trabalho utiliza material de fácil aquisição e manuseio, baixo custo, possibilita a aplicação externa do aparelho no consultório clínico e permite sua remodelagem a cada revisão, sem submeter o animal aos riscos cirúrgicos e anestésicos. Apresentou resultado satisfatório, onde o animal obteve a conformação anatômica fisiológica do tórax com reposicionamento do esterno e restabelecimento da função respiratória.

\section{Abstract}

\section{Funnel chest (Pectus excavatum)}

In a canine with Pectus excavatum a non-invasive technique was used to permit the thoracic anatomic correction with good results.

Key words: Pectus excavatum; thorax; dog

\section{Referências bibliográficas}

Boudrieau RJ, Fossum TW, Hobson HP, Rudy RL 1989. Retrospective evaluation of eight dogs and six cats with pectus excavatum: surgical correction using external splintage in two dogs and one cat. Vet Surg 18: 68-69.

Boudrieau RJ, Fossum TW, Rudy RL, Hartsfield SM, Hobson HP 1990. Pectus excavatum in dogs and cats. Continuing Education Article \# 3, 12(3): 341-355.

Fossum TW, Boudrieau RJ, Hobson HP 1989a. Pectus excavatum in eight dogs and six cats. J Am Animal Hosp Assoc 25: 595-605.

Fossum TW, Boudrieau RJ, Hobson HP, Rudy RL 1989b. Surgical correction of Pectus excavatum, using external splintage in two dogs and a cat. J Am Vet Med Assoc 195(1): 91-97.

McAnulty JF, Harvey CE 1988. Repair of Pectus excavatum by percutaneous suturing and temporary external coaptation in a kitten. J Am Vet Med Assoc 194(8): 1065-1067.

Slater D 1993. Textbook of Small Animal Surgery, p. 561-592, Cap. 43, Stomach,WB Saunders Company.

Sweet DC, Waters DJ 1991. Role of surgery in the management of dogs with pathologic conditions of the thorax - Part II. Continuing Education Article \# 1, 13(11):1671-1676. 